Int. Agrophys., 2019, 33, 49-60

INTERNATIONAL

\title{
Saturated water conductivity estimation based on X-ray CT images - evaluation of the impact of thresholding errors
}

\author{
Bartłomiej Gackiewicz (1)*, Krzysztof Lamorski @ , and Cezary Stawiński (i) \\ Institute of Agrophysics, Polish Academy of Sciences, Doświadczalna 4, 20-290 Lublin, Poland
}

Received May 22, 2018; accepted August 7, 2018

\begin{abstract}
X-ray computed tomography soil studies rely on image analysis procedures that commonly begin with a thresholding step which is prone to errors and leads to uncertainty in the deduced values of soil characteristics, e.g., total porosity, specific surface or simulated saturated water conductivity. In this paper, four 3D images of soil cores were thresholded using two different algorithms. Total porosity and specific surface were determined for binarized images whereas saturated water conductivity was numerically estimated using the Navier-Stokes equation-based modelling. The study shows that an erroneous thresholding step leads to uncertainty in the determination of soil pore system characteristics and saturated water conductivity estimation. The lowest relative error in the total porosity determination, which was obtained in our study, was $15 \%$, and the highest $40 \%$. The results of this study demonstrate that errors related to thresholding may have a huge impact on the estimation of saturated hydraulic conductivity in soils, easily reaching a relative error of $50 \%$ of the saturated water conductivity reference value. Even small shifts in the threshold level can cause huge changes in saturated water conductivity estimation (a threshold shift by $6.7 \%$ for sample 2 analysed in the study caused more than a two-fold increase in the estimated value of saturated hydraulic conductivity).
\end{abstract}

Keywords: X-ray CT, soil porosity, thresholding, water conductivity

\section{INTRODUCTION}

X-ray computed tomography (CT) is a non-destructive imaging technique which can be used to study soil properties related to soil structure, i.e. soil pore space imaging. CT may also be used for imaging the whole soil core samples where a voxel size between $20 \mu \mathrm{m}$ and $50 \mu \mathrm{m}$ is achieved (Jarvis et al., 2017; Rab et al., 2014; Vaz et al., 2011). A resolution of this order allows for macropore observation (Jarvis, 2007; Katuwal et al., 2018; Müller et al., 2018) and root visualization (Daly et al., 2018; Sander et al., 2008). However, it can also be used for imaging soil aggregates

*Corresponding author e-mail: b.gackiewicz@ipan.lublin.pl with a voxel size of $1 \mu \mathrm{m}$ or smaller (Józefaciuk et al., 2015; Voltolini et al., 2017b). A 3D image obtained with this technique, following its processing, allows researchers to examine the inner structure of soil, and to collect information about pore distribution ( $\mathrm{Hu}$ et al., 2015) and pore properties, such as shape factors (Elliot et al., 2010), connectivity (Sleutel et al., 2008) or pore circularity (Yang et al., 2018). The link between soil cores macroporosity and saturated water conductivity has been of special interest (Gerke, 2012; Larsbo et al., 2016; Müller et al., 2018).

In addition to the abovementioned soil characterization options which utilize CT, it is possible to model transport properties in porous materials using spatial models based on CT 3D images. CT-based modelling is an established approach with various applications, including fluid transport (Bultreys et al., 2016; Jiang et al., 2017; Starnoni et al., 2017), fluid-microstructure interaction (Lesueur et al., 2017), petrophysical transport (Liu et al., 2015), immiscible two-phase flow (Liu and $\mathrm{Wu}, 2016$ ), reactive transport (Menke et al., 2017) or carbonate dissolution (Pereira Nunes et al., 2016). The use of real soil structures for building models allows researchers to better understand the pore-scale processes (Daly et al., 2017, 2018; Wildenschild and Sheppard, 2013; Zhang et al., 2016).

However, both the CT-based modelling and the soil characterization methods based on 3D image analyses may be inaccurate. A crucial step in the analysis of CT soil images involves segmentation which is used to divide a $3 \mathrm{D}$ image into solid particles and pore-space. Uncertainty related to threshold level determination is a common problem in the image analysis practice (Baveye et al., 2010; Iassonov et al., 2009). This is especially common when the porespace determination is a result of segmentation although

(C) 2019 Institute of Agrophysics, Polish Academy of Sciences 
one might expect vast differences in the obtained results, and possibly a high impact on the results of modelling based on pore-space geometry. The choice of the segmentation method has a significant impact on the calculation of soil parameters, such as porosity (Baveye et al., 2010). The proper segmentation of a 3D image into solid and porespace is important to create the right $3 \mathrm{D}$ pore-space model. The segmentation step may also be influenced by the image filtering process preceding binarisation (Smet et al., 2018).

There is no standard procedure for image segmentation because of the diversity of porous materials. A 3D CT image consists of voxels of different gray values, reflecting the X-ray absorption in a given space. Therefore, CT image segmentation can be performed by setting the threshold value below or above which voxels will be allocated to one or another set, respectively. Global thresholding, which uses the same threshold value for binarizing the whole image, can be performed manually (Baveye et al., 2010; Moreira et al., 2012) or automatically (Andrä et al., 2013; Daly et al., 2017; Iassonov et al., 2009; Sezgin and Sankur, 2004; Schläuter et al., 2014). A semi-automated approach can also be used (Latief et al., 2017).

However, a CT image is not an ideal representation of X-ray absorption in a given matter. The space in a 3D digital image is discretised, phase boundaries do not usually coincide with boundaries of voxels, and dimensions of some particles can be below the CT resolution (Jones and Feng, 2016). Additionally, other scanning artifacts, such as noise, beam hardening or scattered X-rays (Helliwell et al., 2013; Houston et al., 2013; Wildenschild et al., 2002), can reduce the accuracy of global thresholding.

Another approach involves locally-adaptive segmentation methods (Hapca et al., 2013; Katuwal et al., 2018; Martín-Sotoca et al., 2018; Porter and Wildenschild, 2010). Some of these have been designed especially for binarising the soil media (Hapca et al., 2013; Martín-Sotoca et al., 2018) which utilize spatial information beside the gray level value to assign each voxel to a pore-space or soil matrix. Yet another approach uses both the global thresholding and the locally-adaptive methods (Voltolini et al., 2017a). Although local segmentation methods are known to be generally more accurate, they may be more sensitive to various imperfections of a $\mathrm{CT}$ reconstructed image. Furthermore, local thresholding methods are much more computationally demanding. For these reasons, global thresholding algorithms are still frequently used in practice.

The global thresholding methods considered to be suitable for soil images (Hapca et al., 2013) include Otsu (1979) and Ridler's techniques (Ridler and Calvard, 1978). The Ridler's method, being an iterative self-organizing data analysis technique, is a simple thresholding method which finds application in the study of soil images (Rab et al., 2014; Wang et al., 2011) and images of other porous materials (Chen et al., 2018; Liu et al., 2013; Than et al., 2017).
To ensure the correctness of CT-based soil characterizations, it should be checked whether the 3D model correctly reproduces the actual pore network of the sample. Validation can be performed by comparing the parameters estimated on the basis of a 3D image with those measured in the laboratory. Some of them, like porosity, can be obtained directly from a CT image analysis (Smal et al., 2018) whereas other demand a modelling process. Hydraulic conductivity is a parameter that can be easily obtained through laboratory measurements and estimated in a computer simulation. There are three main approaches to pore-scale modelling, i.e. the lattice Boltzmann method (Gao et al., 2015; McClure et al., 2014), the pore network modelling (Bultreys et al., 2015; Ngom et al., 2011) and the Navier-Stokes (NS) model (Icardi et al., 2014; Muljadi et al., 2016). NS models are differential equations which can be discretised in different manners, e.g. by means of the finite volume method (FVM), the finite difference method (FDM) or the finite element method (FEM). The FVM is popular for its computational efficiency (Bultreys et al., 2016; Meakin and Tartakovsky, 2009) and for the use of unstructured meshes that can be applied easily to complex pore space geometry.

The thresholding step, which usually begins with image analysis procedures, seems to have a crucial impact on the obtained results. This is especially true for the analysis of soil which is a heterogeneous medium that is prone to errors caused by improperly made image binarisation. The impact of the thresholding method on porosity determination for soil media has already been extensively investigated, e.g., by Baveye et al. (2010). Also the impact of thresholding on modelling of the soil water retention curve (SWRC) and deduced from the SWRC unsturated water conductivity was investigated by Beckers et al. (2014). Although several works exist which discuss the possible impact of the segmentation step on different soil media properties, the authors, using their best knowledge, have not come across any analysis related to the possible impact on the modelling of saturated water conductivity. The aim of our work was to evaluate the impact of the possible thresholding inaccuracy on saturated water conductivity estimations. The uncertainty in determining other soil pore-space characteristics, such as total porosity and image specific surface, was also investigated.

\section{MATERIALS AND METHODS}

The paper outline is as follows. The work is based on the analysis of four soil cores which were CT-scanned, whereas 3D images of samples were thresholded using two different algorithms. Total porosity and specific surface were determined for binarised images. For the same images, saturated water conductivity was numerically estimated using NS equation-based modelling. Sensitivity indices were estimated, and the obtained results were analyzed. 
Table 1. Soil samples basic information: sample ID, FAO soil classification, measured saturated water conductivity and parameters obtained from analysis of CT imaging of samples

\begin{tabular}{|c|c|c|c|c|}
\hline \multirow{2}{*}{$\begin{array}{l}\text { Sample ID } \\
\text { FAO soil classification }\end{array}$} & 1 & 2 & 3 & 4 \\
\hline & \multicolumn{2}{|c|}{ Orthic Luvisol } & \multicolumn{2}{|c|}{ Eutric Histosol } \\
\hline ROI length (px) & 1515 & 1564 & 1515 & 1467 \\
\hline Ksat sensitivity ( $\mathrm{m} \mathrm{s}^{-1}$ per gray level unit) & $2.07-05$ & 5.01E-05 & $5.20 \mathrm{E}-06$ & 8.84E-05 \\
\hline Total porosity sensitivity $\left(\mathrm{m}^{3} \mathrm{~m}^{-3}\right.$ per gray level unit) & 0.0017 & 0.0012 & 0.0026 & 0.0058 \\
\hline Specific surface sensitivity $\left(\mathrm{m}^{-1}\right.$ per gray level unit) & 14.19 & 6.37 & 31.22 & 43.77 \\
\hline $\begin{array}{l}\text { Measured SWC }\left(\mathrm{m} \mathrm{s}^{-1}\right) \\
\text { (standard deviation in brackets) }\end{array}$ & $\begin{array}{c}1.74 \mathrm{E}-04 \\
(4.45 \mathrm{E}-06)\end{array}$ & $\begin{array}{l}2.82 \mathrm{E}-04 \\
(4.67 \mathrm{E}-06)\end{array}$ & $\begin{array}{c}5.44 \mathrm{E}-05 \\
(1.22 \mathrm{E}-06)\end{array}$ & $\begin{array}{c}4.34 \mathrm{E}-04 \\
(2.59 \mathrm{E}-06)\end{array}$ \\
\hline \multicolumn{5}{|c|}{ Thresholding method: default } \\
\hline Threshold value (-) & 132 & 105 & 88 & 82 \\
\hline Image total porosity $\left(\mathrm{m}^{3} \mathrm{~m}^{-3}\right)$ & 0.15 & 0.13 & 0.17 & 0.33 \\
\hline Image specific surface $\left(\mathrm{m}^{-1}\right)$ & 1323.89 & 744.01 & 2097.19 & 3286.10 \\
\hline Estimated saturated water conductivity $\left(\mathrm{m} \mathrm{s}^{-1}\right)$ & $1.03 \mathrm{E}-03$ & $1.36 \mathrm{E}-03$ & $1.66 \mathrm{E}-04$ & $2.22 \mathrm{E}-03$ \\
\hline \multicolumn{5}{|c|}{ Thresholding method: isodata } \\
\hline Threshold value (-) & 91 & 88 & 61 & 63 \\
\hline Image total porosity $\left(\mathrm{m}^{3} \mathrm{~m}^{-3}\right)$ & 0.09 & 0.11 & 0.10 & 0.22 \\
\hline Image specific surface $\left(\mathrm{m}^{-1}\right)$ & 741.92 & 635.70 & 1254.29 & 2454.45 \\
\hline Estimated saturated water conductivity $\left(\mathrm{m} \mathrm{s}^{-1}\right)$ & $1.81 \mathrm{E}-04$ & $5.08 \mathrm{E}-04$ & $2.57 \mathrm{E}-05$ & $5.41 \mathrm{E}-04$ \\
\hline
\end{tabular}

For the purpose of this study, four soil cores were tested, and two soil types (described in Table 1) differing in microstructure were chosen. Samples 1 and 2 are mineral (Orthic Luvisol) soil while samples 3 and 4 are organic peat soil (Eutric Histosol). Cores were sampled from two different locations by taking two samples from each location. The samples were taken from arable layers, five centimetres below the soil surface. Sampling took place in the spring 2017 when soil moisture was high enough to use plastic cylinders for sampling. Soil moisture also allowed for the sampling to be performed without the risk of soil structure destruction. Plastic cylinders were $45 \mathrm{~mm}$ in diameter and $40 \mathrm{~mm}$ in height, and they were not as strong and stiff as metal ones but had a lower X-ray absorbance. The collected samples remained in cylinders for CT scans, in order not to change the structure of the sampled soil. Just after their collection, the samples were sealed with Parafilm to prevent water loss due to evaporation, which could lead to shrinking of the soil sample and, consequently, to changes in its structure.

The samples placed in plastic cylinders were examined using an X-ray computational micro-tomograph GE Nanotom 180 S at the IA PAS X-ray CT facility (Lamorski, 2017). Parameters of the X-ray tube were as follows: the accelerating voltage $100 \mathrm{kV}$, the cathode current $150 \mu \mathrm{A}$, and a tungsten exit window. An exit window filter was not used. During the scan, a series of 1200 2D images were registered by rotating the sample by $0.3^{\circ}$ stepwise for a full 360 -degree rotation. For noise reduction purposes, each 2D image was averaged out of 20 records that were $750 \mathrm{~ms}$ each, which were acquired with a slight (by a few pixels) random perpendicular angle to the X-ray beam detector movements. The 2D images were registered with a 14-bit gray level depth by a flat panel detector with a resolution of $2284 \times 2304$ pixels.

After the X-ray CT examination of the samples, saturated water conductivity of the cores was measured repeatedly, using the constant head method (Eijkelkamp Soil and Water, The Netherlands) (Table 1).

The 3D reconstruction, using the collected 2D images, was performed with $\mathrm{CT}$ software (datos $\mid \mathrm{x}$ version 2.0.1, General Electric). It was necessary to use the software beam hardening correction offered by $\mathrm{CT}$ reconstruction software. The spatial resolution of the 3D reconstructed volume, i.e. voxel size, was $23.6 \mu \mathrm{m}$ in each direction. The 3D images were saved as 16-bit tiff files. The selection of the cylindrical region of interest (ROI) for further processing, based on the reconstructed 3D volume, as well as the filtering process were performed using Avizo 9 (Thermo Fisher Scientific). The ROI had a cylindrical shape with a diameter 1878 pixels. The ROI height were slightly different for different samples and are presented in Table 1. The image was filtered twice for noise reduction, using a 3D median filter with a cross-shaped 3D kernel, with a diameter equal to 3 pixels. After the thresholding, pore size distribution was performed, which consisted of two steps, i.e. pore-space splitting and labelling. After the labelling, the dataset was generated with individual pore volumes and pore equivalent diameters. 
a)

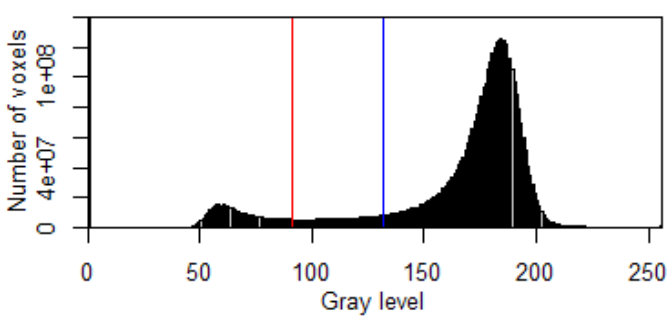

c)

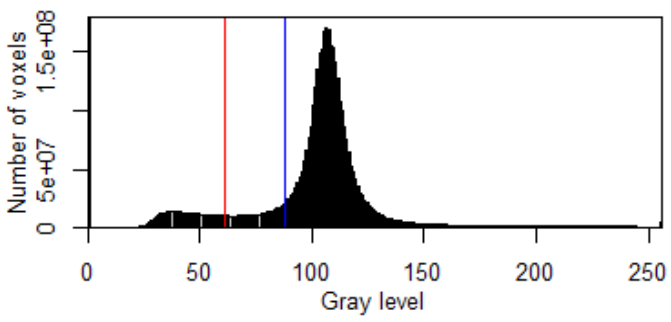

b)

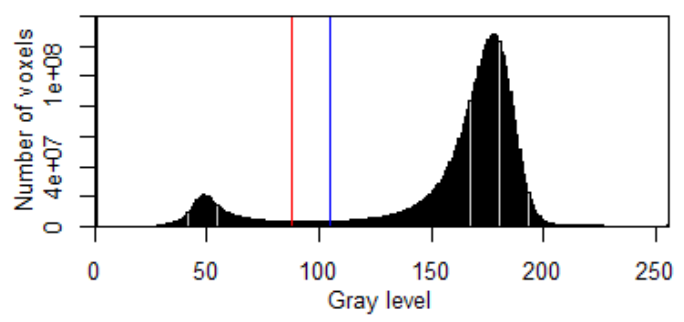

d)

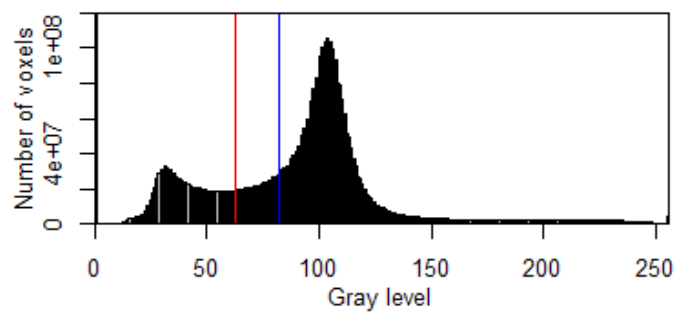

Fig. 1. Histograms of the scanned soil cores: a) - sample 1, b) - sample 2, c) - sample 3, d) - sample 4 with marked values of the isodata threshold (red line) and the default threshold (blue line).

The filtered 16-bit 3D images of soils were converted into an 8-bit grayscale. The histograms (for the whole 3D image) of the scanned samples are shown in Fig. 1. Three of them are clearly bimodal (i.e. one can observe two maxima in the histogram) although the peak corresponding to the solid is much larger than the one corresponding to the pore space. Then, the 3D images were thresholded to distinguish pore-space from the soil solid phase, within the accuracy level for which the $\mu \mathrm{CT}$ scan resolution was achieved. Two different threshold methods were applied in respect of all the 3D images. The thresholding was performed using the Fiji image processing software (Schindelin et al., 2012). Two global thresholding algorithms available in Fiji, i.e. 'Default' and 'Isodata', were used to this end. Both methods are variations of Ridler's iterative intermeans algorithm (Ridler and Calvard, 1978). The difference between both algorithms is that the 'Default' method uses some additional histogram pre-processing prior to applying the intermeans algorithm. The pre-processing modifies the maximum peak in the cases where it is more than twice higher in relation to the other. The images that were thresholded by the Default and Isodata methods will be hereinafter referred to as 'the Default threshold' and 'the Isodata threshold', respectively.

The process of thresholding consisted of two stages. Firstly, a single slice (an example of the slice is shown in Fig. 2) was arbitrarily chosen as the most representative (with no artifacts, clearly observed pores and a structure similar to other slices) for the whole 3D volume, based on which a histogram of gray values was calculated. The obtained gray level threshold value was used rather than binarizing the whole 3D volume. This approach was based on the selection of a representative slice for threshold calculation, instead of determining separate thresholds for each slice in the stack to avoid incorrect thresholding results for the slices without proper pore representation (Iassonov et al., 2009).
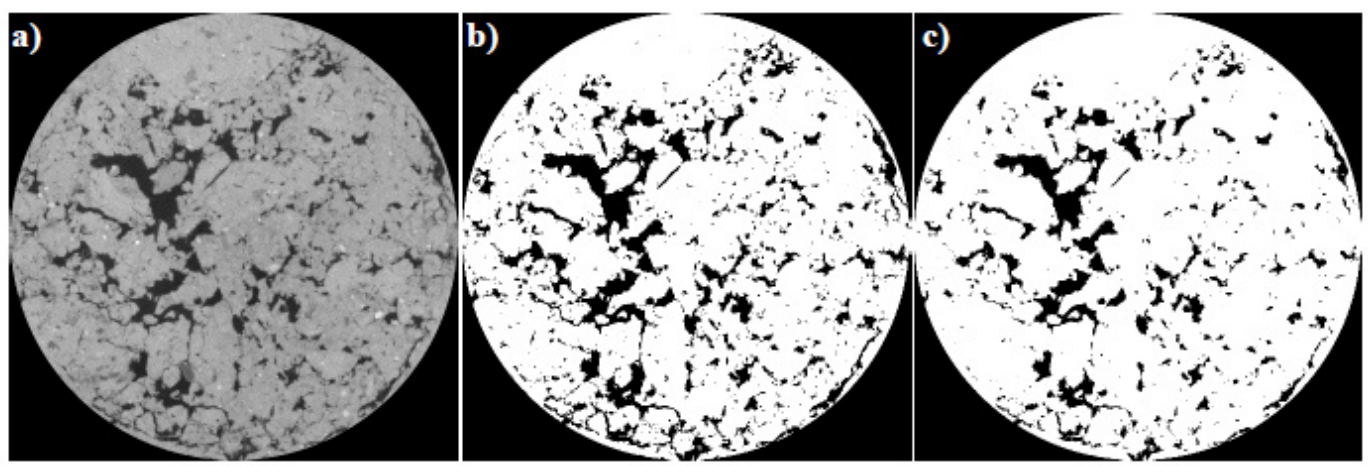

Fig. 2. A selected slice from Sample 1 stack: a) an 8-bit gray level image, b) default thresholding c) isodata thresholding. 
In this study, two different algorithms of thresholding were evaluated. The reasons for choosing these algorithms were of a twofold nature. Firstly, they are commonly used for porous media studies including soils (Hapca et al., 2013) and, secondly, the evaluation of different algorithms based on the thresholding of selected slices from soil cores shows more optimal results in comparison with other approaches. There is one specific aspect of the algorithms in question which qualifies them for application to the soil core segmentation task, i.e. they do not rely on the assumption of the bimodal character of the histograms of segmented images as does, for example, the popular Otsu method. It is uncommon to see true bimodal histograms in X-ray CT soil related studies, due to the fact that CT-detected pores only form a small fraction of the scanned core volume $\lesssim 0.2$. The Otsu method has also been used in soil related CT studies, e.g., in the work by Jarvis et al. (2017).

The threshold values are presented in Table 1 in a 256degree scale, where 0 corresponds to the black voxels and 255 represents white voxels.

In the thresholded binary image, there are two types of voxels representing pore-space and soil solid phases. Such a voxelized surface of the pore-space would not be a good representation of the physical surface. It was interpolated using the triangulation method with a BoneJ plugin (Doube et al., 2010) and then saved as a STL file for further use in numerical mesh generation. The image total porosity and the image specific surface were also determined (Table 1). The image specific surface $\sigma\left(\mathrm{m}^{-1}\right)$ was calculated as the area of a triangulated surface $\left(\mathrm{m}^{2}\right)$ divided by the ROI volume $\left(\mathrm{m}^{3}\right)$.

For transport modelling, NS equations were used. The set of NS equations comprises the momentum balance Eq. (1) and the continuity Eq. (2), where $u$ is a velocity vector $\left(\mathrm{m} \mathrm{s}^{-1}\right), \rho$ is fluid density $\left(\mathrm{kg} \mathrm{m}^{-3}\right), p$ is pressure $\left(\mathrm{kg} \mathrm{m}^{-1} \mathrm{~s}^{-2}\right)$, $\mu$ is dynamic viscosity $\left(\mathrm{kg} \mathrm{m}^{-1} \mathrm{~s}^{-1}\right), \tau$ is a strain rate tensor $\left(\mathrm{s}^{-1}\right), \bar{F}$ are external forces ( $\mathrm{kg} \mathrm{m} \mathrm{s}^{-2}$ ) (Eq. (3)), and $\bar{g}$ is gravitational acceleration $\left(\mathrm{m} \mathrm{s}^{-2}\right)$ :

$$
\begin{gathered}
u_{j} \frac{\partial}{\partial x_{j}}\left(\rho u_{i}\right)=-\frac{\partial p}{\partial x_{i}}+\mu \frac{\partial \tau_{i j}}{\partial x_{j}}+\bar{F}, \\
\frac{\partial}{\partial x_{j}}\left(\rho u_{j}\right)=0,
\end{gathered}
$$

$$
\bar{F}=p \bar{g} .
$$

It was implemented by means of the OpenFOAM CFD software, using FVM differential equation discretisation. For the simulation purpose, a non-compressible steadystate laminar single phase flow was assumed. The flow domain was the CT-determined sample macropore network while the remaining part of the sample was treated as a nonpermeable solid body.

OpenFOAM uses unconstrained and unstructured meshes which are especially suitable for the meshing of complex pore-space geometry. The numerical mesh was created on the basis of the STL file with a triangulated surface of the soil solid phase, using snappyHexMesh a native OpenFOAM meshing tool which allows for the meshing of non-uniform complex geometries. Mesh cells were generated only for the pore-space regions of soil, and for additional thin layers connected with pores at both the input and output on which boundary conditions were enforced. However, OpenFOAM software focuses on generating high quality mesh, although in such a complex meshed geometry as in the case of pore-space some of the mesh cells do not always meet quality constraints. To avoid such potential problems, the created mesh was checked for the occurrence of cells with highly skewed faces. Faces with the skewness value being higher than four were deleted. The presence of cells with highly skewed faces could impair the quality of the results and make the calculations unstable. The number of deleted cells is shown in Table 2 . As it did not exceed $0.003 \%$ of the total number of cells, it can be assumed that the impact of deleted cells on the geometry of the whole image was negligible.

The numerical mesh simulations were performed using a steady-state simpleFoam solver. The appropriate boundary conditions were set up in the simulation process, i.e. the value of fluid velocity was fixed to $1 \mathrm{e}-5 \mathrm{~m} \mathrm{~s}^{-1}$, and the pressure was established at $0 \mathrm{~Pa}$ on the input patch with zero gradient Neuman conditions on the output patch. The input and output patches were equivalent to the top and bottom portions of the soil sample. No-slip boundary conditions were applied to the pore walls.

The water flow simulation mimics the constant head saturated conductivity measurement principle. Saturated hydraulic conductivity $K_{s}\left(\mathrm{~m} \mathrm{~s}^{-1}\right)$ can be estimated based

\begin{tabular}{|c|c|c|c|c|}
\hline \multirow{2}{*}{ Sample ID } & \multicolumn{2}{|c|}{ Default thresholding } & \multicolumn{2}{|c|}{ Isodata thresholding } \\
\hline & Total no. of cells & No. of cells removed & Total no. of cells & No. of cells removed \\
\hline 1 & 15902446 & 122 & 8972655 & 52 \\
\hline 2 & 10860072 & 19 & 7591906 & 21 \\
\hline 3 & 10962708 & 313 & 42175764 & 312 \\
\hline 4 & 24569148 & 631 & 14582346 & 330 \\
\hline
\end{tabular}

Table 2. Statistic of numerical mesh used for SWC modeling (total No. of cells - total number of cells in the mesh, No. of cells removed - number of cell removed from mesh due to quality constraints) 
on information about pressure difference $\Delta p\left(\mathrm{~kg} \mathrm{~m}^{-1} \mathrm{~s}^{-2}\right)$ between the input and output patches, fluid velocity at the input patch $u\left(\mathrm{~m} \mathrm{~s}^{-1}\right)$ and flow domain length $\Delta l(\mathrm{~m})$ :

$$
K_{s}=u \rho g \frac{\Delta l}{\Delta p},
$$

where: $g\left(\mathrm{~m} \mathrm{~s}^{-2}\right)$ stands for gravitational constant and $\rho$ $\left(\mathrm{kg} \mathrm{m}^{-3}\right)$ for fluid density.

A sensitivity analysis allows for estimating the impact of the perturbation in the model's input parameters on the model's output. The local sensitivity analysis is used for sensitivity estimation for a given value or a set of selected values of input parameters. On the other hand, the global sensitivity analysis allows for the general quantification of sensitivity for the whole range of input parameters.

More general approaches are available for sensitivity estimation, including the one-factor-at-a-time method (OAT), the Morris method or variance decomposition based methods (Saltelli et al., 2002). In the simplest cases where local sensitivity estimation is needed and models input parameters are not correlated, a differential sensitivity analysis can be performed (Hamby, 1994) instead.

The differential sensitivity analysis is based on the assumption that sensitivity coefficient $S_{i}$ for a particular independent variable $X_{i}$ may be estimated by the partial derivative of dependent variable $Y$ (i.e. the model's output) with respect to an independent variable (i.e. the model's parameter):

$$
S_{i}=\left.\frac{\partial Y}{\partial X_{i}}\right|_{X_{i}} .
$$

Obviously, in practical applications partial derivatives have to be estimated by finite differences because the models are not usually described by analytical functions which could be differentiated.

\section{RESULTS AND DISCUSSION}

The intermeans algorithm based thresholding procedures, which was used in this study, unlike the popular Otsu method, does not rely on the histogram bimodality assumption. In the soil samples studied, the problem of histogram non-bimodality can also be observed, as evidenced in the histograms for samples 2 and 4 (Fig. 1b, d). These samples are bimodal, although the maximum values related to pores are much lower than the maximum values related to the soil matrix. However, it is hard to treat the histograms of samples 1 and 3 as bimodal, especially since the histogram of sample 3 completely lacks this feature (Fig. 1a, c).

Two different variations of the iterative intermeans algorithm were evaluated in this study, i.e. Default and Isodata. For the examined samples, the threshold values were always higher in the case of the Default thresholding algorithm. The higher value of the threshold is connected with a higher number of voxels categorized as corresponding to the pore space and, hence, with higher porosity. As can be observed in Fig. 1, different values of thresholds are determined using different validated algorithms. The Isodata threshold algorithm always places a lower value of the threshold which means that the smaller part of the sample's volume is considered to be a pore-space. Differences in the threshold levels determined by these two algorithms ranged from 17 to 41 units, where 8-bit depth and 256 gray levels were used for CT image representation. Similar values of the threshold levels achieved by different algorithms were reported (Smet et al., 2018) for soil media. A sample slice from the stack representing sample 1 is presented in Fig. 2. It can be seen that the default thresholding algorithm area of the pores on this cross-section is bigger than in the case of the Isodata algorithm. The differences in total porosity that were detected using CT for the presented samples were as follows: $0.06,0.02,0.07$ and 0.11 , respectively (Fig. 3). It means that the minimum change in porosity was $15 \%$, and the maximum change was $40 \%$, in relation to the porosities determined by means of the Default algorithm (Table 1). Both porosities, determined for the Default and Isodata thresholded media, are well-correlated, $\mathrm{R}^{2}=0.9$ (Fig. 4).

These results show that the potential impact of the improper selection of the thresholding method on porosity results is high, and this phenomenon has already been identified in literature (Baveye et al., 2010). The sensitivity indices which were calculated and analyzed in the study confirm this point of view (Table 1). If we assumed the possible uncertainty in the threshold level determination at ten units, corresponding to $4 \%$, it would cause uncertainty in the total porosity determination of at least $10 \%$ for sample 1 (with 17\% being the highest value calculated for sample 4). So, an erroneous determination of the threshold value propagates a porosity determination error and boosts it substantially. It is worth mentioning that 10 uncertainty units used in the present discussion reflect a realistic assumption as far as differences in the threshold level determination are concerned (Wang et al., 2011). The differences in the threshold level determination in soil studies may be even higher (Beckers et al., 2014).

Threshold changes exert a varied impact on pores with different sizes, which is reflected in the cumulative pore distribution (Fig. 5). In the case of samples 1 and 2, pores with different volumes increase proportionally for the samples thresholded by means of the Default and Isodata algorithms. In the case of samples 3 and 4, the volume of pores with an equivalent radius up to $\sim 0.1-0.2 \mathrm{~mm}$ increases proportionally whereas pores with higher radiuses, up to $\sim 0.7 \mathrm{~mm}$, dominate in the case of the Isodata thresholded samples. Finally, once the radius value of $\sim 0.7 \mathrm{~mm}$ was achieved in both samples 3 and 4, thresholded by the Default algorithm, an increase in the volume of largest pores wass observed. It means that the larger pores in samples 3 and 4 predominantly contribute to an increase in the total pore-system volume of these samples. 
a)

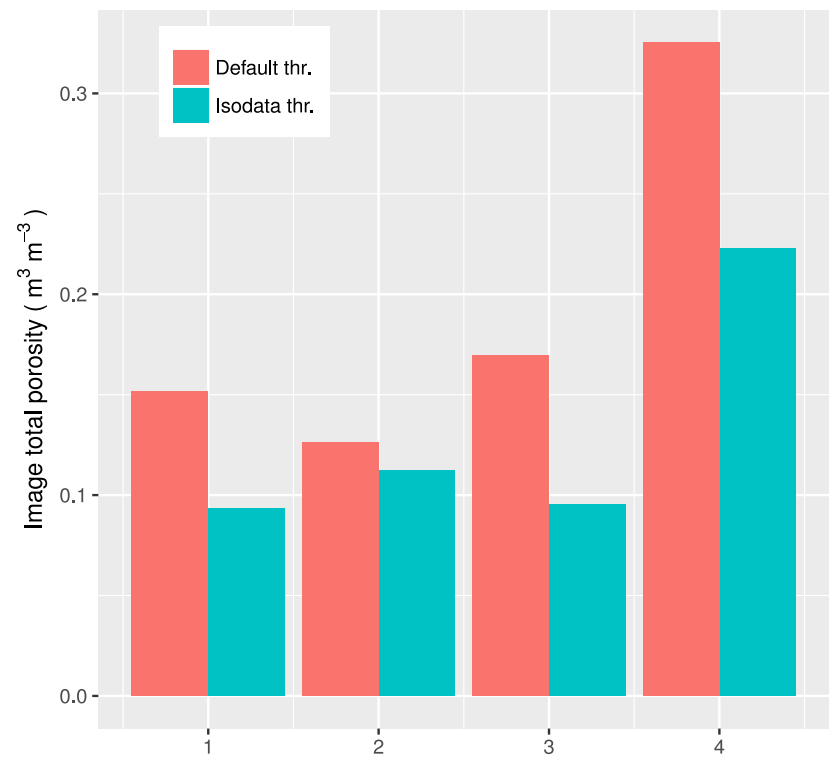

b)

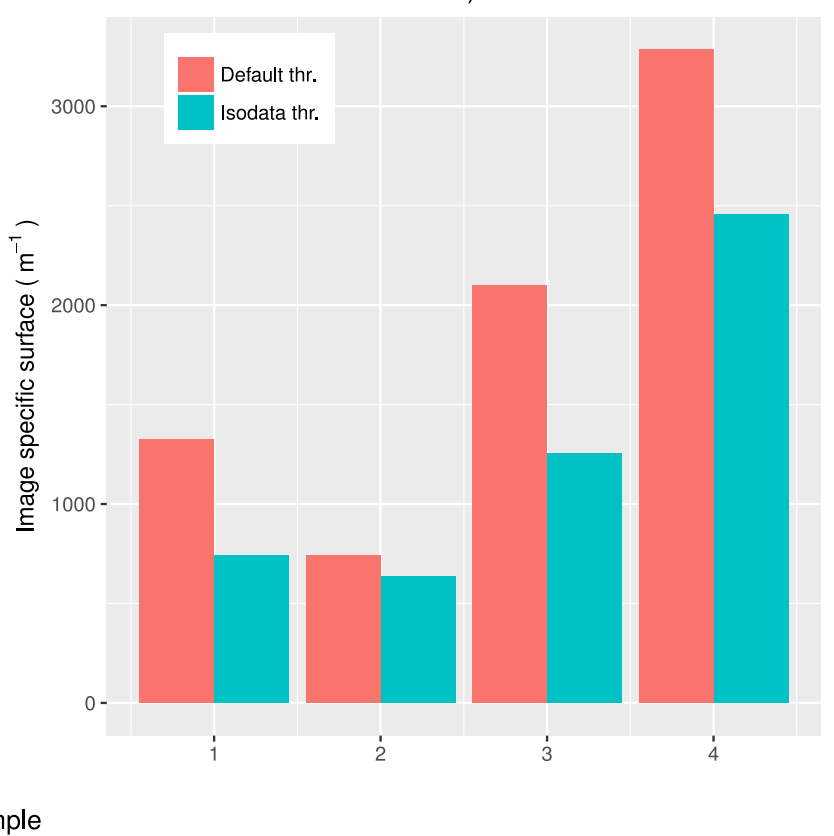

Fig. 3. Values of the image total porosity (a) and the image specific surface (b) determined on the basis of 3D soil images thresholded with the Isodata method (red) and the Default (green) method.

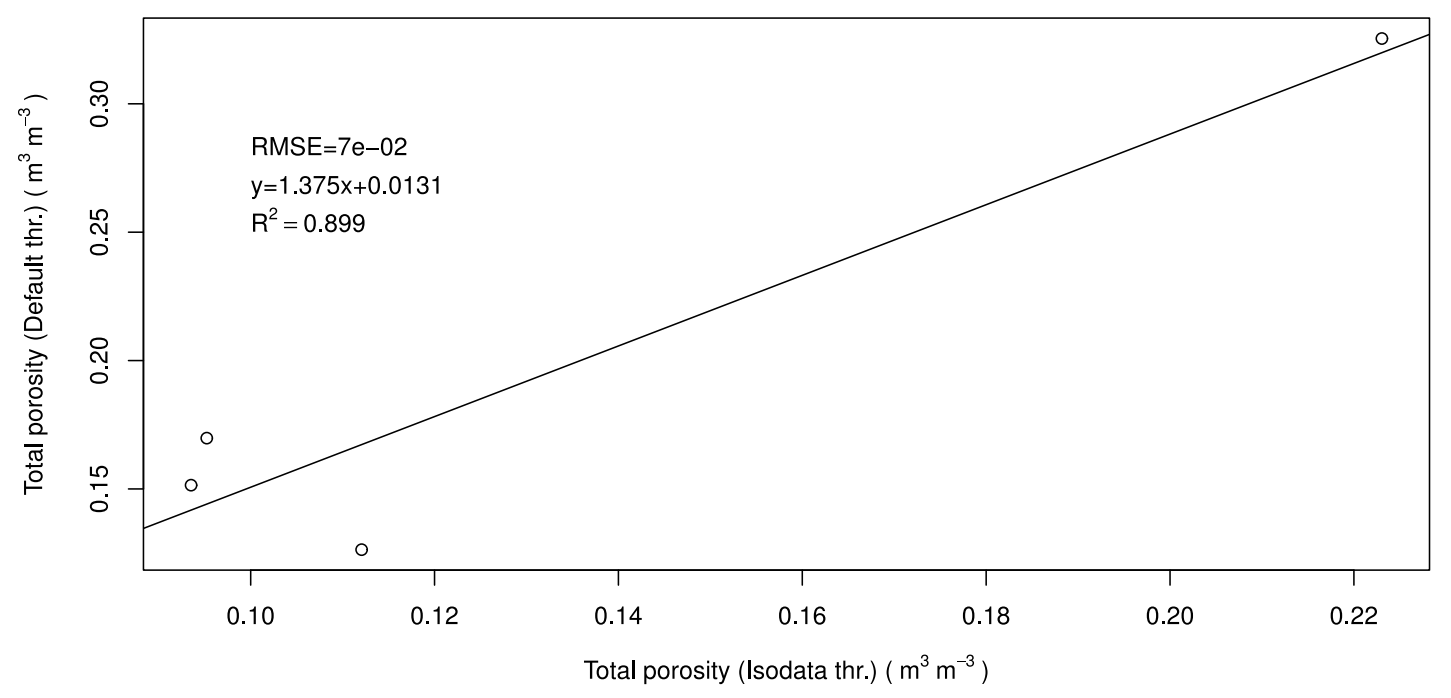

Fig. 4. Relationship between the image total porosity on the basis of the Isodata and Default thresholded soil images (p-value for the linear model presented: 0.05208).

As in the case of total porosity, the image specific surface is also dependent on the threshold methods applied in the image analysis workflow (Fig. 3). The highest change in specific surface is observed for sample $1-80 \%$, and smallest for sample $2-17 \%$, in relation to the default thresholding method (Table 1). Both characteristics are well-correlated, $\mathrm{R}^{2}=0.95$ (Fig. 6). The sensitivity analysis allows us to estimate the potential impact of the threshold level determination inaccuracy on the image specific surface determination. Assuming the same threshold determination uncertainty, i.e. reaching ten units of inaccuracy, the specific surface determination would be at least $64\left(\mathrm{~m}^{-1}\right)$ and maximum inaccuracy would be $437\left(\mathrm{~m}^{-1}\right)$.

Two simulations based on different thresholding methods were made, and different values of saturated hydraulic conductivity estimations were obtained (Fig. 7). Values of the SWC estimated with the NS model on the basis of the default threshold are well correlated with the corresponding 
a)

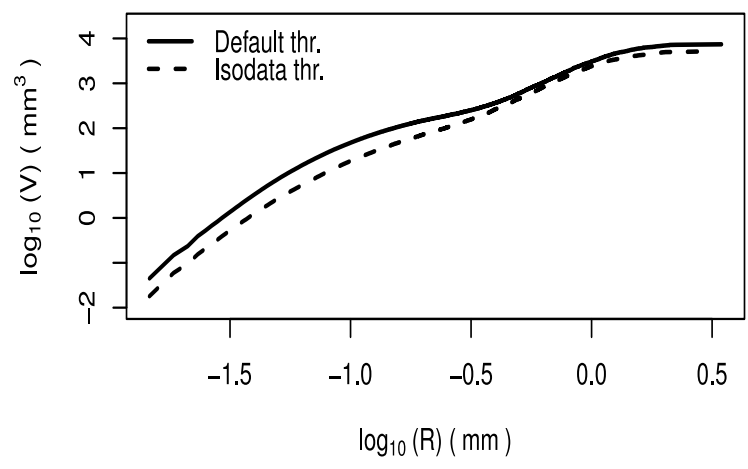

c)

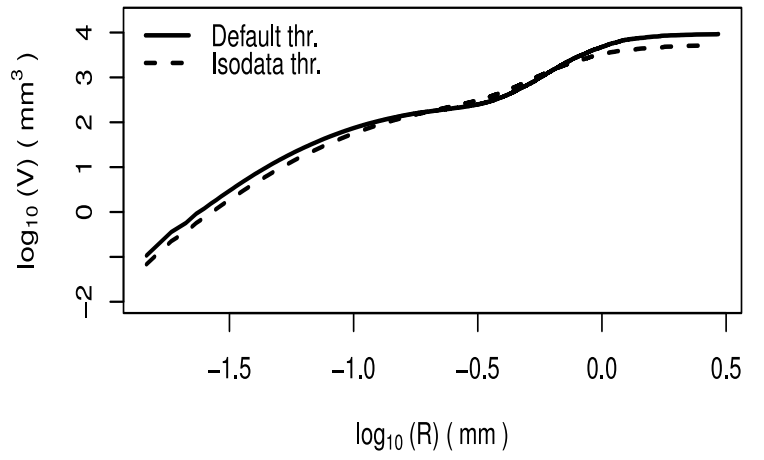

b)

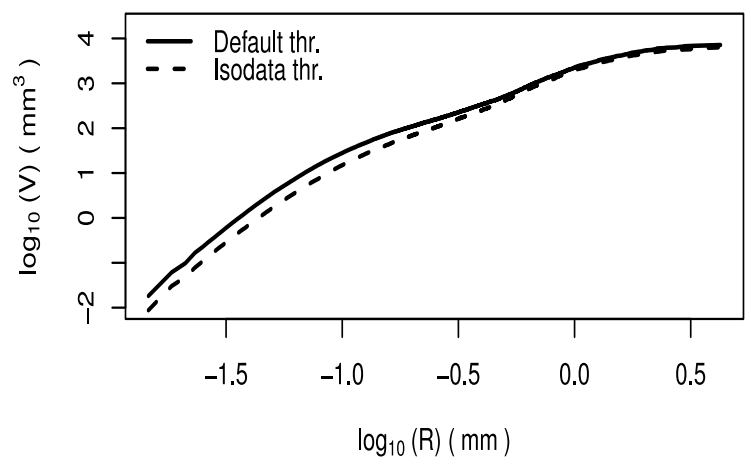

d)

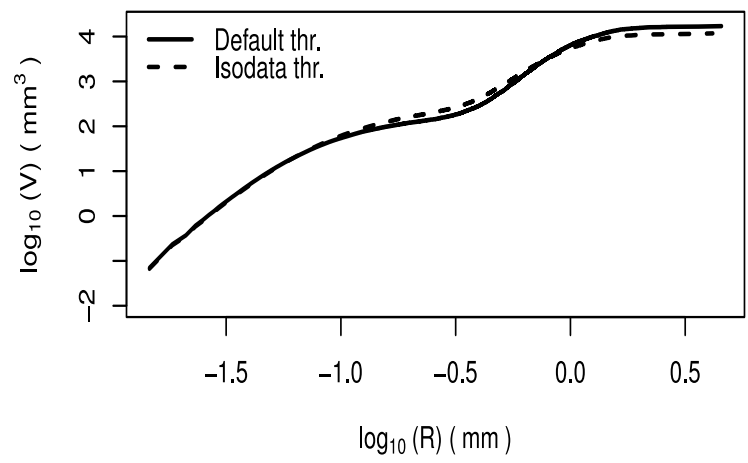

Fig. 5. Cumulative pore volume distributions for pore spaces (R-equivalent pore radius) determined using the Default algorithm (continuous line) and the Isodata algorithm (dashed line). a - sample 1, b - sample 2, c - sample 3, d-sample 4.

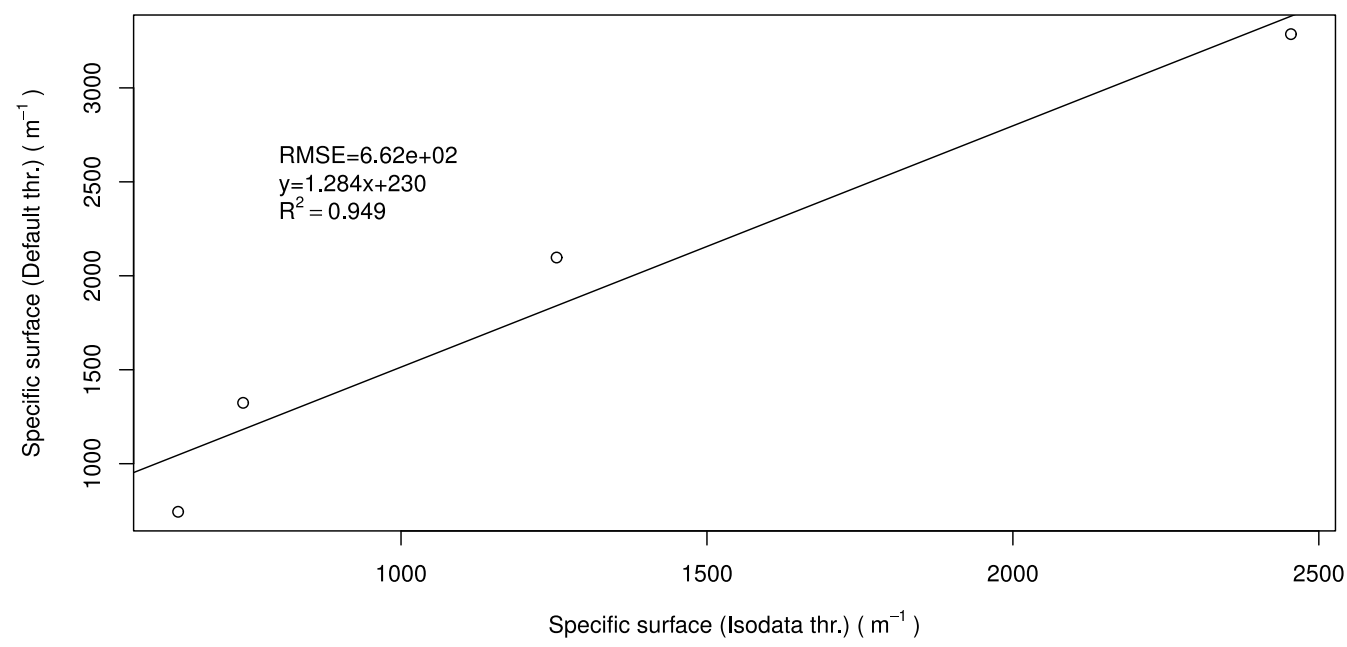

Fig. 6. Relationship between the image specific surfaces calculated on the basis of the isodata and default thresholded soil images (p-value for the linear model presented: 0.02605). 


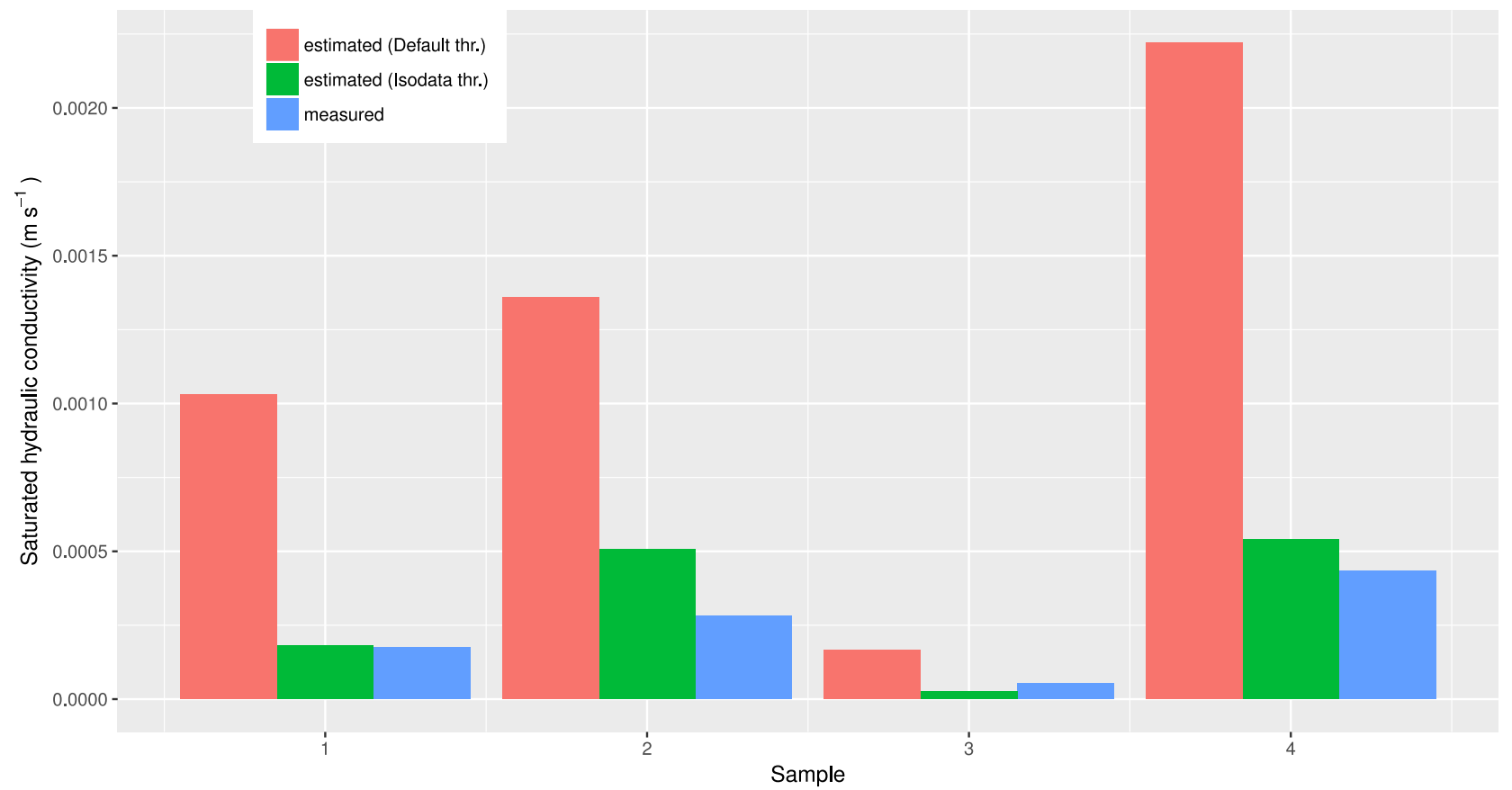

Fig. 7. Saturated water conductivity: estimations based on differently-thresholded images and laboratory measurements.

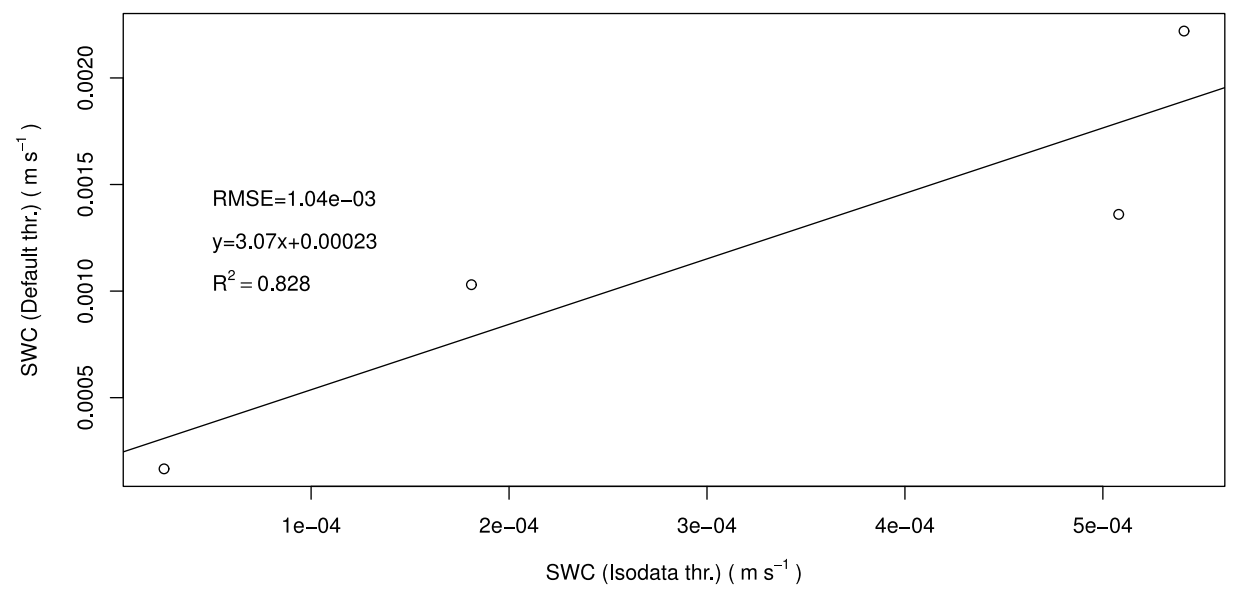

Fig. 8. Relationship between the saturated hydraulic conductivity estimated on the basis of the isodata and default thresholded soil images (p-value for the linear model presented: 0.09025).

values estimated by means of the Isodata threshold, $\mathrm{R}^{2}=0.83$. The Isodata-based estimations are, on average, three times lower than the Default thresholding-based estimations (Fig. 8). Both estimations are highly correlated with the measured values of SWC $\left(\mathrm{R}^{2}=0.98\right.$ for Default thresholding and $\mathrm{R}^{2}=0.88$ for Isodata thresholding), but the Default threshold-based simulations overestimate five times saturated water conductivity (Fig. 9), when compared with the measured values. The Isodata threshold-based simulations are much accurate, with only a slight $\sim 1.5$ overestimation.
The local sensitivity indices calculated for SWC (Table 1) show a strong dependence of the SWC on the potential uncertainty related to threshold level determination. The lowest Ksat sensitivity coefficient value is $\sim 5.2 \mathrm{e}-6$, and the highest $\sim 8.8 \mathrm{e}-5\left(\mathrm{~m} \mathrm{~s}^{-1}\right.$ per gray level unit]. If the previous assumption of the uncertainty related to threshold level determination was adopted at 10 gray level units, it would lead to the uncertainty in SWC estimation ranging from $5.2 \mathrm{e}-5$ to $8.8 \mathrm{e}-4\left(\mathrm{~m} \mathrm{~s}^{-1}\right)$, based on the results of our study. If these errors were compared to the SWC estimations based on the Default threshold, they would correspond to relative error values of 20 and $40 \%$, respectively. 


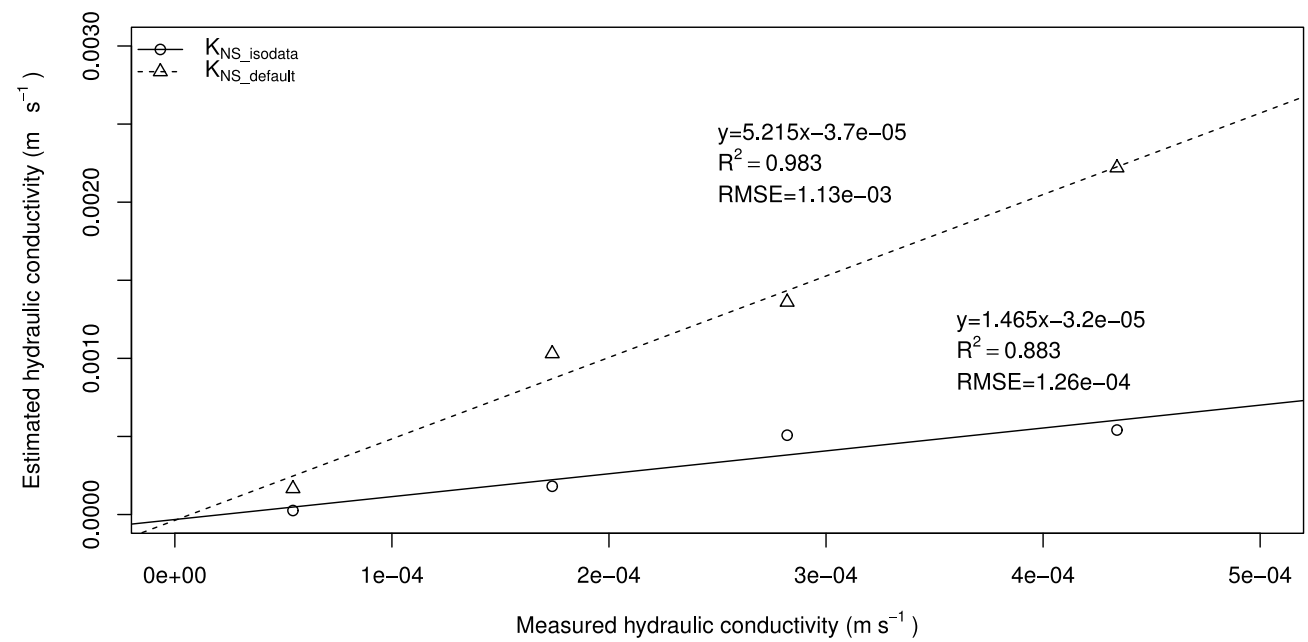

Fig. 9. Relationship between the measured SWC value and the SWC value estimated using the Isodata (continuous line) and Default thresholded (dashed line) pore-space images, based on NS simulations (p-value for the KNS_isodata linear model presented: 0.06036, p-value for the KNS_default linear model presented: 0.00876).

\section{CONCLUSIONS}

1. The results of this study demonstrate that thresholding-related errors may have a huge impact on the estimation of saturated hydraulic conductivity in soils, easily reaching a relative error that accounts for $50 \%$ of the saturated water conductivity reference value.

2. Even small shifts in the threshold level can cause huge changes in saturated water conductivity estimations. For instance, a threshold shift of $6.7 \%$ for sample 2 caused more than a two-fold increase in the value of saturated hydraulic conductivity.

3. Soil images are hard to threshold automatically because their histograms do not display explicit bimodality, which eventually leads to thresholding errors. This is caused by the relatively small pore-space fraction observed in the computed tomography images of soils.

4. The sensitivity of computed tomography-based estimations of saturated water conductivity on thresholding shows that the values estimated through modelling should be validated.

Conflict of interest: The authors declare no conflict of interest.

\section{REFERENCES}

Andrä H., Combaret N., Dvorkin J., Glatt E., Han J., Kabel M., Keehm Y., Krzikalla F., Lee M., Madonna C., Marsh M., Mukerji T., Saenger E.H., Sain R., Saxena N., Ricker S., Wiegmann A., and Zhan X., 2013. Digital rock physics benchmarks-Part I: Imaging and segmentation. Comput. Geosci., 50, 25-32. doi:10.1016/j.cageo.2012.09.005

Baveye P.C., Laba M., Otten W., Bouckaert L., Dello Sterpaio P., Goswami R.R., Grinev D., Houston A., Hu Y., Liu J., Mooney S., Pajor R., Sleutel S., Tarquis A., Wang W.,
Wei Q., and Sezgin M., 2010. Observer-dependent variability of the thresholding step in the quantitative analysis of soil images and X-ray microtomography data. Geoderma, 157, 51-63. doi:10.1016/J.GEODERMA.2010.03.015

Beckers E., Plougonven E., Roisin C., Hapca S., Léonard A., and Degré A., 2014. X-ray microtomography: A porositybased thresholding method to improve soil pore network characterization? Geoderma, 219-220, 145-154, doi:10. 1016/j.geoderma.2014.01.004

Bultreys T., De Boever W., and Cnudde V., 2016. Imaging and image-based fluid transport modeling at the pore scale in geological materials: A practical introduction to the current state-of-the-art. Earth-Science Rev., 155, 93-128. doi:10.1016/J.EARSCIREV.2016.02.001

Bultreys T., Van Hoorebeke L., and Cnudde V., 2015. Multiscale, micro-computed tomography-based pore network models to simulate drainage in heterogeneous rocks. Adv. Water Resour., 78, 36-49. doi:10.1016/J.ADVWATRES. 2015.02.003

Chen X., Verma R., Espinoza D.N., and Prodanović M., 2018. Pore-scale determination of gas relative permeability in hydrate-bearing sediments using X-ray computed microtomography and lattice Boltzmann method. Water Resour. Res. 54, 600-608. doi:10.1002/2017WR021851

Daly K.R., Cooper L.J., Koebernick N., Evaristo J., Keyes S.D., van Veelen A., and Roose T., 2017. Modelling water dynamics in the rhizosphere. Rhizosphere, 4, 139-151. doi:10.1016/J.RHISPH.2017.10.004

Daly K.R., Tracy S.R., Crout N.M.J., Mairhofer S., Pridmore T.P., Mooney S.J., and Roose T., 2018. Quantification of root water uptake in soil using X-ray computed tomography and image-based modelling. Plant. Cell Environ., 41, 121-133. doi:10.1111/pce.12983

Doube M., Klosowski M.M., Arganda-Carreras I., Cordelières F.P., Dougherty R.P., Jackson J.S., Schmid B., Hutchinson J.R., and Shefelbine S.J., 2010. BoneJ: Free and extensible bone image analysis in Image J. Bone, 47, 1076-1079. doi:10.1016/j.bone.2010.08.023 
Elliot T.R., Reynolds W.D., and Heck R.J., 2010. Use of existing pore models and X-ray computed tomography to predict saturated soil hydraulic conductivity. Geoderma, 156, 133142. doi:10.1016/j.geoderma.2010.02.010

Gao J., Xing H., Rudolph V., Li Q., and Golding S.D., 2015. Parallel lattice Boltzmann computing and applications in core sample feature evaluation. Transp. Porous Media, 107, 65-77. doi:10.1007/s11242-014-0425-1

Gerke H.H., 2012. Macroscopic representation of the interface between flow domains in structured soil. Vadose Zo. J., 11, 0. doi:10.2136/vzj2011.0125

Hamby D.M., 1994. A review of techniques for parameter sensitivity analysis of environmental models. Environ. Monit. Assess., 32, 135-154. doi:10.1007/BF00547132

Hapca S.M., Houston A.N., Otten W., and Baveye P.C., 2013. New local thresholding method for soil images by minimizing grayscale intra-class variance. Vadose Zo. J., 12, 0. doi:10.2136/vzj2012.0172

Helliwell J.R., Sturrock C.J., Grayling K.M., Tracy S.R., Flavel R.J., Young I.M., Whalley W.R., and Mooney S.J., 2013. Applications of $X$-ray computed tomography for examining biophysical interactions and structural development in soil systems: a review. Eur. J. Soil Sci., 64, 279-297. doi:10.1111/ejss.12028

Houston A.N., Schmidt S., Tarquis A.M., Otten W., Baveye P.C., and Hapca S.M., 2013. Effect of scanning and image reconstruction settings in X-ray computed microtomography on quality and segmentation of 3D soil images. Geoderma, 207-208, 154-165. doi:10.1016/J.GEODERMA. 2013.05.017

Hu X., Li Z.-C., Li X.-Y., and Liu Y., 2015. Influence of shrub encroachment on CT-measured soil macropore characteristics in the Inner Mongolia grassland of northern China. Soil Till. Res., 150, 1-9. doi:10.1016/j.still.2014.12.019

Iassonov P., Gebrenegus T., and Tuller M., 2009. Segmentation of X-ray computed tomography images of porous materials: A crucial step for characterization and quantitative analysis of pore structures. Water Resour. Res., 45. doi: 10.1029/2009WR008087

Icardi M., Boccardo G., Marchisio D.L., Tosco T., and Sethi R., 2014. Pore-scale simulation of fluid flow and solute dispersion in three-dimensional porous media. Phys. Rev., E 90, 013032. doi:10.1103/PhysRevE.90.013032

Jarvis N., Larsbo M., and Koestel J., 2017. Connectivity and percolation of structural pore networks in a cultivated silt loam soil quantified by X-ray tomography. Geoderma, 287, 71-79. doi:10.1016/j.geoderma.2016.06.026

Jarvis N.J., 2007. A review of non-equilibrium water flow and solute transport in soil macropores: principles, controlling factors and consequences for water quality. Eur. J. Soil Sci., 58, 523-546. doi:10.1111/j.1365-2389.2007.00915.x

Jiang Z., van Dijke M.I.J., Geiger S., Ma J., Couples G.D., and Li X., 2017. Pore network extraction for fractured porous media. Adv. Water Resour., 107, 280-289. doi:10.1016/j. advwatres.2017.06.025

Jones B.D., and Feng Y.T., 2016. Effect of image scaling and segmentation in digital rock characterisation. Comput. Part. Mech., 3, 201-213. doi:10.1007/s40571-015-0077-0

Józefaciuk G., Czachor H., Lamorski K., Hajnos M., Świeboda R., and Franus W., 2015. Effect of humic acids, sesquioxides and silica on the pore system of silt aggregates measured by water vapour desorption, mercury intrusion and microtomography. Eur. J. Soil Sci., 66, 992-1001. doi:10.1111/ejss. 12299

Katuwal S., Hermansen C., Knadel M., Moldrup P., Greve M.H., and de Jonge L.W., 2018. Combining X-ray computed tomography and visible near-infrared spectroscopy for prediction of soil structural properties. Vadose Zo. J., 17, 0. doi:10.2136/vzj2016.06.0054

Lamorski K., 2017. X-ray computational tomography facility Institute of Agrophysics PAS [WWW Document]. URL http://tomography.ipan.lublin.pl/ (accessed 4.19.18).

Larsbo M., Koestel J., Kätterer T., and Jarvis N., 2016. Preferential transport in macropores is reduced by soil organic carbon. Vadose Zo. J. 15, 0. doi:10.2136/vzj2016.03.0021

Latief F.D.E., Fauzi U., Irayani Z., and Dougherty G., 2017. The effect of X-ray micro computed tomography image resolution on flow properties of porous rocks. J. Microsc., 266, 69-88. doi:10.1111/jmi.12521

Lesueur M., Casadiego M.C., Veveakis M., and Poulet T., 2017. Modelling fluid-microstructure interaction on elasto-viscoplastic digital rocks. Geomech. Energy Environ., 12, 1-13. doi:10.1016/J.GETE.2017.08.001

Liu J., Song R., and Cui M., 2015. Improvement of predictions of petrophysical transport behavior using three-dimensional finite volume element model with micro-CT images. J. Hydrodyn., Ser. B, 27, 234-241. doi:10.1016/S10016058(15)60477-2

Liu Y., Wang H., Shen Z., and Song Y., 2013. Estimation of $\mathrm{CO}_{2}$ storage capacity in porous media by using X-ray micro-CT. Energy Procedia, 37, 5201-5208. doi:10.1016/J.EGYPRO. 2013.06.436

Liu Z., and Wu H., 2016. Pore-scale modeling of immiscible two-phase flow in complex porous media. Appl. Therm. Eng., 93, 1394-1402. doi:10.1016/j.applthermaleng.2015. 08.099

Martín-Sotoca J.J., Saa-Requejo A., Grau J.B., and Tarquis A.M., 2018. Local 3D segmentation of soil pore space based on fractal properties using singularity maps. Geoderma, 311, 175-188. doi:10.1016/J.GEODERMA.2016.11.029

McClure J.E., Prins J.F., and Miller C.T., 2014. A novel heterogeneous algorithm to simulate multiphase flow in porous media on multicore CPU-GPU systems. Comput. Phys. Commun., 185, 1865-1874. doi:10.1016/J.CPC.2014.03.012

Meakin P., and Tartakovsky A.M., 2009. Modeling and simulation of pore-scale multiphase fluid flow and reactive transport in fractured and porous media. Rev. Geophys., 47, RG3002. doi:10.1029/2008RG000263

Menke H.P., Bijeljic B., and Blunt M.J., 2017. Dynamic reservoir-condition microtomography of reactive transport in complex carbonates: Effect of initial pore structure and initial brine pH. Geochim. Cosmochim. Acta, 204, 267-285. doi:10.1016/j.gca.2017.01.053

Moreira A.C., Appoloni C.R., Mantovani I.F., Fernandes J.S., Marques L.C., Nagata R., and Fernandes C.P., 2012. Effects of manual threshold setting on image analysis results of a sandstone sample structural characterization by X-ray microtomography. Appl. Radiat. Isot., 70, 937-941. doi:10.1016/J.APRADISO.2012.03.001

Muljadi B.P., Blunt M.J., Raeini A.Q., and Bijeljic B., 2016. The impact of porous media heterogeneity on non-Darcy 
flow behaviour from pore-scale simulation. Adv. Water Resour., 95, 329-340. doi:10.1016/J.ADVWATRES.2015. 05.019

Müller K., Katuwal S., Young I., McLeod M., Moldrup P., de Jonge L.W., and Clothier B., 2018. Characterising and linking X-ray CT derived macroporosity parameters to infiltration in soils with contrasting structures. Geoderma, 313, 82-91. doi:10.1016/j.geoderma.2017.10.020

Ngom N.F., Garnier P., Monga O., and Peth S., 2011. Extraction of three-dimensional soil pore space from microtomography images using a geometrical approach. Geoderma, 163, 127-134. doi:10.1016/j.geoderma.2011.04.013

Otsu N., 1979. A threshold selection method from gray-level histograms. IEEE Trans. Syst. Man. Cybern., 9, 62-66. doi:10.1109/TSMC.1979.4310076

Pereira Nunes J.P., Blunt M.J., and Bijeljic B., 2016. Porescale simulation of carbonate dissolution in micro-CT images. J. Geophys. Res. Solid Earth, 121, 558-576. doi:10.1002/2015JB012117

Porter M.L., and Wildenschild D., 2010. Image analysis algorithms for estimating porous media multiphase flow variables from computed microtomography data: a validation study. Comput. Geosci., 14, 15-30. doi:10.1007/ s10596-009-9130-5

Rab M.A., Haling R.E., Aarons S.R., Hannah M., Young I.M., and Gibson D., 2014. Evaluation of X-ray computed tomography for quantifying macroporosity of loamy pasture soils. Geoderma, 213, 460-470. doi:10.1016/J. GEODERMA.2013.08.037

Ridler T.W. and Calvard S., 1978. Picture thresholding using an iterative selection method. IEEE Trans. Syst. Man Cybern., 8, 630-632. doi:10.1109/TSMC.1978.4310039

Saltelli A., Tarantola S., Campolongo F., and Ratto M., 2002. Sensitivity analysis in practice. John Wiley and Sons, Ltd, Chichester, UK. doi:10.1002/0470870958

Sander T., Gerke H.H., and Rogasik H., 2008. Assessment of Chinese paddy-soil structure using X-ray computed tomography. Geoderma, 145, 303-314. doi:10.1016/j.geoderma. 2008.03.024

Schindelin J., Arganda-Carreras I., Frise E., Kaynig V., Longair M., Pietzsch T., Preibisch S., Rueden C., Saalfeld S., Schmid B., Tinevez J.-Y., White D.J., Hartenstein V., Eliceiri K., Tomancak P., and Cardona A., 2012. Fiji: an open-source platform for biologicalimage analysis. Nat. Methods, 9, 676-682. doi:10.1038/ nmeth.2019

Schläuter S., Sheppard A., Brown K., and Wildenschild D., 2014. Image processing of multiphase images obtained via X-ray microtomography: A review. Water Resour. Res., 50, 3615-3639. doi:10.1002/2014WR015256.Received

Sezgin M., and Sankur B., 2004. Survey over image thresholding techniques and quantitative performance evaluation. J. Electron. Imaging, 13, 146-165. doi:10.1117/1.1631316

Sleutel S., Cnudde V., Masschaele B., Vlassenbroek J., Dierick M., Van Hoorebeke L., Jacobs P., and De Neve S., 2008. Comparison of different nano- and micro-focus X-ray computed tomography set-ups for the visualization of the soil microstructure and soil organic matter. Comput. Geosci., 34, 931-938. doi:10.1016/j.cageo.2007.10.006
Smal P., Gouze P., and Rodriguez O., 2018. An automatic segmentation algorithm for retrieving sub-resolution porosity from X-ray tomography images. J. Pet. Sci. Eng., 166, 198207. doi:10.1016/J.PETROL.2018.02.062

Smet S., Plougonven E., Leonard A., Degré A., and Beckers E., 2018. X-ray Micro-CT: how soil pore space description can be altered by image processing. Vadose Zo. J., 17, 0 . doi:10.2136/vzj2016.06.0049

Starnoni M., Pokrajac D., and Neilson J.E., 2017. Computation of fluid flow and pore-space properties estimation on microCT images of rock samples. Comput. Geosci., 106, 118-129. doi:10.1016/j.cageo.2017.06.009

Than V. Du, Tang A.M., Roux J.-N., Pereira J.M., Aimedieu P., and Bornert M., 2017. Investigation into macroscopic and microscopic behaviors of wet granular soils using discrete element method and X-ray computed tomography. In: Powders and Grains, 8th Int. Conf. Micromechanics on Granular Media, July 3-7, Montpellier, France, doi:10.1051/ epjconf/201714008018

Vaz C.M.P., de Maria I.C., Lasso P.O., and Tuller M., 2011. Evaluation of an advanced benchtop micro-computed tomography system for quantifying porosities and pore-size distributions of two Brazilian oxisols. Soil Sci. Soc. Am. J. 75, 832. doi:10.2136/sssaj2010.0245

Voltolini M., Kwon T.-H., and Ajo-Franklin J., 2017a. Visualization and prediction of supercritical $\mathrm{CO}_{2}$ distribution in sandstones during drainage: An in situ synchrotron X-ray micro-computed tomography study. Int. J. Greenh. Gas Control, 66, 230-245. doi:10.1016/J.IJGGC.2017.10.002

Voltolini M., Taş N., Wang S., Brodie E.L., and Ajo-Franklin J.B., 2017b. Quantitative characterization of soil microaggregates: New opportunities from sub-micron resolution synchrotron X-ray microtomography. Geoderma, 305, 382393. doi:10.1016/J.GEODERMA.2017.06.005

Wang W., Kravchenko A.N., Smucker A.J.M., and Rivers M.L., 2011. Comparison of image segmentation methods in simulated $2 \mathrm{D}$ and $3 \mathrm{D}$ microtomographic images of soil aggregates. Geoderma, 162, 231-241. doi:10.1016/J. GEODERMA.2011.01.006

Wildenschild D., Hopmans J.W., Vaz C.M.P., Rivers M.L., and Rikard D., 2002. Using X-ray computed tomography in hydrology: systems, resolutions, and limitations. J. Hydrol., 267, 285-297.

Wildenschild D., and Sheppard A.P., 2013. X-ray imaging and analysis techniques for quantifying pore-scale structure and processes in subsurface porous medium systems. Adv. Water Resour., 51, 217-246. doi:10.1016/j.advwatres.2012. 07.018

Yang Y., Wu J., Zhao S., Han Q., Pan X., He F., and Chen C., 2018. Assessment of the responses of soil pore properties to combined soil structure amendments using X-ray computed tomography. Sci. Rep., 8, 695. doi:10.1038/s41598-01718997-1

Zhang X., Crawford J.W., Flavel R.J., and Young I.M., 2016. A multi-scale Lattice Boltzmann model for simulating solute transport in 3D X-ray micro-tomography images of aggregated porous materials. J. Hydrol., 541, 1020-1029. doi:10.1016/j.jhydrol.2016.08.01 